\title{
Una perspectiva comparada sobre el concepto de marca, el régimen de los signos distintivos notorios y las prohibiciones de registro en las normativas española y nicaragüense
}

\author{
Enrique Barrero Rodríguez ${ }^{48}$ \\ Universidad de Sevilla, España
}

Fecha de recibido: septiembre 2016 / Fecha de aprobación: diciembre 2016

Resumen

La importancia de las marcas como modalidades de propiedad industrial resulta incuestionable para el moderno Derecho mercantil. En España y Nicaragua el régimen jurídico de los signos distintivos se contiene respectivamente en las Leyes 17/200I, de Marcas y 380, de Marcas y Otros Signos Distintivos. Ambas leyes asientan su regulación sobre rasgos comunes y sobre la exigencia de fuerza distintiva de la marca, aunque con diversidad de matices que obedecen a la distinta influencia de la tradición jurídica sobre la que se asientan. En el presente estudio se realiza una aproximación comparativa de algunos de los aspectos de dichas regulaciones, fundamentalmente el concepto de marca, y el régimen legal de las marcas notorias y de las prohibiciones de registro

\section{Palabras Clave}

\section{Ley / Marcas / Signos distintivos}

\section{Abstract}

The importance of trademarks as industrial property type is unquestionable for modern commercial law. In Spain and Nicaragua the legal status of the distinctive signs contained respectively in Law 17/200I Trademark and 380, on Trademarks and Other Distinctive Signs. Both laws settle its regulation on common features and on the requirement of distinctive brand strength, although with a variety of nuances that are due to the influence of different legal tradition on which they are based. In the present study a comparative approach of some aspects of these regulations, mainly the brand concept and the legal regime of the notorious marks and prohibitions registration is done.

\section{Key Words}

Law / Trademarks / Distinctive signs

\footnotetext{
${ }^{48}$ Profesor Titular de Universidad en la Facultad de Derecho de la Universidad de Sevilla, Doctor en Derecho por la Universidad de Sevilla, España.
} 
I. Planteamiento. II. Diferencias en la delimitación conceptual de la marca. III. Apunte sobre la regulación de los signos distintivos notorios. I. Regulación en España. 2. Regulación en Nicaragua. 3. Algunas diferencias entre ambas regulaciones. IV. La regulación de las prohibiciones de registro. I. Presupuesto. 2. Prohibiciones absolutas o fundamentadas en razones intrínsecas. 3. Prohibiciones relativas o fundamentadas en derechos de terceros. V. Consideración final. Lista de referencias.

\section{Planteamiento}

En el presente estudio, tal y como da cuenta la acotación de su título, nos proponemos analizar con una perspectiva esencialmente comparativa los rasgos esenciales de algunos aspectos concretos de las normativas sobre marcas española y nicaragüense, aunque no, naturalmente, todas las múltiples y muy variadas cuestiones reguladas por ambas normativas. Básicamente, vamos a centrarnos en tres aspectos fundamentales de esa modalidad esencial de propiedad industrial constituida por las marcas, como son el concepto de estos signos distintivos, el régimen jurídico de los signos distintivos notorios $y$, en particular y finalmente, las prohibiciones de registro de marcas establecidas con un enfoque sustancialmente coincidente en ambas normativas. Para el cumplimiento de este objetivo vamos a utilizar un enfoque metodológico esencialmente apegado a la exposición del Derecho positivo vigente, a partir de la literalidad de las normas reguladoras de la cuestión e intentando perfilar sus similitudes y diferencias básicas.

Como resulta suficientemente conocido el Derecho de marcas constituye una de las modalidades esenciales de la denominada genéricamente propiedad industrial. Tal y como ha puesto de manifiesto la mejor doctrina industrialista española (Fernández-Nóvoa, C. (2004). p. 27) "la marca es un bien inmaterial; esto es, un bien que no tiene una existencia sensible, sino que, por el contrario, necesita materializarse en cosas tangibles". No resulta necesario enfatizar la importancia de las marcas para las diferentes economías nacionales y, en último término, para la Economía mundial en su conjunto, dado el escenario de globalización en el que actualmente tienden a desarrollarse las relaciones económicas en un contexto progresivo en el que viene a reducirse y a atenuarse la importancia de las fronteras y a matizarse la compartimentación y fragmentación de los derechos nacionales (Olivencia, M. (2007), septiembre 25, p. 3), por ello, aunque la regulación sobre las marcas pueda presentar lógicas diferencias de enfoque o de matiz en cada Ordenamiento jurídico, el camino a seguir en el futuro consideramos, como en tantas otras materias jurídicas, que debe ser el de la unificación progresiva y el de la concordancia y homogeneización de las diferentes soluciones legales ante los diversos problemas jurídicos comunes que puedan plantearse en la materia.

En el presente trabajo pretendemos realizar una aproximación de conjunto, y de naturaleza esencialmente comparativa, entre las legislaciones marcarias española y nicaragüense, una aproximación que dé cuenta de los rasgos esenciales de ambas normativas y pueda aportar, modestamente, una perspectiva integradora y de mutuo enriquecimiento, aun partiendo de la constatación inequívoca del hecho de que se trata de regulaciones que responden a tradiciones y a sistemas jurídicos diversos entre las que cabe apreciar diferencias sustanciales. Una primera diferencia, que no por constituir un simple matiz terminológico deja de tener importancia, atañe a la propia rúbrica de los textos legales respectivos. 
Así, mientras que en España la regulación de los signos distintivos se contiene en la Ley 17/2001, de 7 de diciembre, de Marcas, publicada en el Boletín Oficial del Estado número 294, de 8 de diciembre de 200I (sobre esta Ley y las novedades que introdujo en el Ordenamiento jurídico español me permito remitir a Barrero, E. (2002). y a Arroyo, I. (2002). I5-43), en Nicaragua la Ley número 380 de 200 I tiene el título de Ley de Marcas y Otros Signos Distintivos (para una aproximación general a esta Ley nicaragüense y su contenido cabe remitir al interesante estudio de investigación de González, L.V. (20I3). recuperado de Universidad Centroamericana, sitio web: http://repositorio.uca.edu.ni/65).

Vaya por adelantado que, sin perjuicio de las observaciones que realizaremos posteriormente en relación con el contenido sustantivo de la regulación contenida en ambos textos legales, la rúbrica de la Ley nicaragüense nos parece más acertada y expresiva que la de la norma española por su deliberada y más omnicomprensiva amplitud, pues la Ley española comete la imprecisión de aludir en su rúbrica exclusivamente a las marcas siendo así que a lo largo de su articulado aborda la regulación no solo de las marcas sino también la de los nombres comerciales (Título $X$, comprensivo de los artículos 87 a 91), configurados como aquellos signos que identifican en el tráfico mercantil a las empresas y sirven para distinguirlas de las restantes empresas que desarrollan actividades idénticas o similares. Más acertadamente, por tanto, la normativa nicaragüense acomoda su rúbrica a la amplitud de su regulación, dado que su articulado regula no solo las marcas, en tanto su artículo 2 acoge las definiciones, igualmente, de denominación de origen, emblema, nombre comercial, nombre de dominio o rótulo.

\section{Diferencias en la delimitación conceptual de la marca}

Desde un punto de vista teórico, el concepto de marca suele gozar de una relativa unidad doctrinal y se asienta esencialmente sobre la potencialidad distintiva de la marca en relación con los productos o servicios que designa, de ahí que, en la doctrina española, Lema, C. \& Fernández, P. (20I3) I7I afirmen que "la característica fundamental de las marcas es su carácter distintivo, el cual no ha de valorarse en abstracto, sino en relación con los concretos productos o servicios que designa". Es dicha naturaleza distintiva del signo en cuestión la que confiere su naturaleza esencial a las marcas y, al mismo tiempo, le permite cumplir la más trascendental de sus funciones, que no es otra que la de permitir a los consumidores formarse una idea cabal de la naturaleza y de la calidad de los productos ofrecidos por las diferentes empresas, dado que, en último término y como se ha señalado oportunamente, "la marca es el vehículo de la competencia" (Robleto, C. \& Hermida, V.. (2008). p. 29).

Desde el punto de vista normativo tanto el Derecho español como el nicaragüense forman parte de los Ordenamientos jurídicos que formulan un concepto legal de marca y que, en consecuencia y tal y como ha destacado la doctrina (Fernández-Nóvoa (2004), p. 38) presentan la ventaja de proporcionar al intérprete un valioso instrumento que le permite determinar los signos que pueden constituir una marca.

Este cometido y naturaleza definitoria de las leyes no ha resultado doctrinalmente pacífico, pues no han faltado autores que han recordado que la función de las leyes debe ser eminentemente normativa y no conceptual, recordando el viejo aforismo de que toda definición en Derecho resulta potencialmente conflictiva y peligrosa (omnis enim definitio in iure periculosa est). No obstante, tanto la normativa española como la nicaragüense han optado por definir legalmente la marca y la definición que en ambas normativas 
se establece, mucho más si cabe en la norma centroamericana, resulta una definición de extraordinaria elasticidad. Para un análisis profundo y en detalle de los tres sistemas teóricamente imaginables para la definición de la marca y un análisis exhaustivo y en detalle del concepto formulado por la norma nicaragüense y su sentido y antecedentes remitimos a la Tesis Doctoral de Mati Hernández Alfaro dirigida por el profesor Otero Lastres, La registrabilidad de la marca en el Derecho nicaragüense, recuperada I 5 de septiembre de 2016, en Biblioteca Digital Universidad de Alcalá, http://hdl.handle.net/I0017/2056, pp. IOI y siguientes.

Vamos a continuación a reproducir dichos conceptos aportados por las respectivas normas para centrarnos posteriormente en el análisis de sus concomitancias y diferencias.

Conforme al artículo 4 de la Ley española 17/200I "se entiende por marca todo signo susceptible de representación gráfica que sirva para distinguir en el mercado los productos o servicios de una empresa de los de otras". Debe destacarse que se trata de un concepto cuya formulación presentaba como objetivo último la convergencia y alineamiento con el concepto de marca formulado en el ámbito europeo. En efecto, el artículo 2 de la Directiva europea 89/104 declara que "podrán constituir marcas todos los signos que puedan ser objeto de una representación gráfica, especialmente las palabras, incluidos los nombres de las personas, los dibujos, las letras, las cifras, la forma del producto o de su presentación, a condición de que tales signos sean apropiados para distinguir los productos o servicios de una empresa de los de otras". Cabe también destacar, en segundo término, que este concepto resultó extraordinariamente novedoso en el Ordenamiento jurídico español respecto del formulado en la Ley de marcas anterior, la Ley de Marcas 32/1988, básicamente al insertar como nuevo requisito del signo, con el aludido objetivo de convergencia literal con la anteriormente citada Directiva europea, el requisito de la susceptibilidad de representación gráfica del signo en cuestión, no contemplado por la normativa precedente.

Por su parte, el artículo 2 de la Ley nicaragüense 380 de 200 l contiene una definición de la marca más breve y escueta que la de la Ley española al definir la marca como "cualquier signo que sea apto para distinguir productos o servicios". Hay que precisar, en relación con los signos susceptibles de constituir signos distintivos, que en el Ordenamiento jurídico nicaragüense la Ley de marcas y otros signos distintivos fue reformada y adicionada por la Ley número 580 de 21 de marzo de 2006 publicada en la Gaceta Diario Oficial número 60 de 24 de marzo de 2006 (sobre el alcance de estas modificaciones puede consultarse Bendaña-Guerrero, G.J. (20II). I25-I43).

Conviene partir de la premisa de que tanto la Ley española como la nicaragüense coinciden en lo esencial, que es la conceptuación de la marca como un signo y en la explicitación de la más esencial de sus funciones, que es su aptitud distintiva de los productos o servicios. Esta delimitación de la marca como un signo que realiza tanto la normativa española como la centroamericana merece un sucinto comentario porque puede llegar a suscitar algún reparo teórico en el caso de que llegue a abanderarse una interpretación exclusivamente literalista y restrictiva de la noción de signo y quizá no hubiera resultado necesaria tan precisa acotación, que lleva algún tiempo evidenciando su potencial conflictividad en el Derecho de Marcas. En España, por ejemplo, la normativa derogada sobre marcas contenida en la Ley 32/1988 definía la marca como todo signo o medio. En términos de análoga alternatividad, el Convenio 
Centroamericano para la Protección de la Propiedad Industrial vino a definir la marca como todo signo, palabra o combinación de palabras o cualquier otro medio, gráfico o material, que por sus caracteres fuera susceptible de distinguir claramente los productos, mercancías o servicios de la misma especie o clase pero de diferente titular. La tendencia posterior, sin embargo, y en esto han venido a coincidir tanto el Derecho español como el centroamericano, ha sido la de suprimir la referencia a la marca como medio y su limitación a la configuración como signo. Entiendo modestamente que en el Derecho nicaragüense ello genera cierta contradicción y antinomia con la más que generosa enumeración de signos que pueden constituir marca contenida en el artículo 3 de la Ley 380 y que llega, tras las adiciones operadas por la mencionada Ley 580, a la propia admisión como marca de los olores o la ya tradicional de las formas de presentación o acondicionamiento de los productos. Es más, el propio artículo 3 de la Ley 380 admite como marca los propios medios o locales de expendio de los productos o servicios.

Esta limitación de la marca a los signos (que entendemos que encuentra su fundamento lógico en el artículo 2 del Protocolo de Modificación al Convenio Centroamericano para la Protección de la Propiedad Industrial al definir la marca como "cualquier signo visible” y que influyó en la literalidad de la redacción inicial de la legislación sobre marcas y signos distintivos nicaragüense) entendemos que puede llegar a pugnar con la elegante generalidad, flexibilidad y generosidad del sistema de marcas nicaragüense en lo tocante a la configuración de la marca. No se olvide que de las numerosas acepciones del término signo conforme al Diccionario de la Real Academia de la Lengua española signo se define, en bastantes de ellas, como "señal o figura que se emplea en la escritura" o, incluso, "marca gráfica que se emplea en la lengua escrita". Consideramos, por todo ello, en nuestra muy modesta y respetuosa apreciación, que el concepto de marca no se hubiera resentido particularmente si hubiera sido definida en la legislación nicaragüense como "cualquier signo o medio apto para distinguir productos o servicios" en lugar de signo que sea apto para distinguir productos o servicios".

Más allá de esta coincidencia que hemos advertido del precepto español y del nicaragüense en lo esencial (la función distintiva de la marca) de la confrontación de la literalidad de ambos preceptos y de la comparación general de los sistemas español y nicaragüense cabe deducir, en cuanto a las diferencias en la formulación del concepto legal de marca, las siguientes conclusiones:

a) El precepto definitorio de La Ley nicaragüense resulta de más acentuada concisión, diríase incluso que de más exacerbado laconismo, que el de la norma análoga española. Efectivamente, el artículo 2 de la Ley 380 carece de toda acotación locativa y objetiva a la noción de marca, frente a las acotaciones que realiza la Ley española. La norma nicaragüense no contiene referencia alguna a que la aptitud distintiva de las marcas lo sea para la presencia de los productos o servicios en el mercado $y$, de idéntico modo, omite toda referencia implícita a la titularidad de la marca, frente a la dicción literal de la norma hispana, que indica expresamente que la marca distingue los productos “de una empresa de los de otras".

Entendemos que esta opción resulta acertada, pues en el contexto de una actividad económica plural la experiencia demuestra cómo son numerosas las asociaciones de muy diverso signo, no propia ni típicamente encuadrables dentro de la noción económica clásica de empresa, que recurren a la solicitud de registro de signos distintivos para la protección de sus emblemas. La 
definición nicaragüense, por consiguiente, resulta una definición que bien podríamos denominar quintaesenciada, en tanto incide en la característica esencial de la marca que es su aptitud distintiva de los productos o servicios, despojando el concepto de cualquier otro matiz o adherencia innecesaria desde el punto de vista de la función distintiva estricta de la marca.

Es evidente que esta concisión del artículo 2 de la Ley 380 persigue un objetivo general de flexibilidad y de amplitud en cuanto a la formulación del concepto de marca, toda vez que la tendencia del Derecho de la propiedad industrial en los últimos tiempos es la de admitir junto a las marcas tradicionales nuevas modalidades de marcas originales o no convencionales en cuanto a su topografía o configuración, como las marcas sonoras, olfativas o táctiles. Es más, la anteriormente referida Ley 580 por la que se modifica y adiciona la Ley 380 ha ampliado el elenco de signos que pueden constituir marca conforme al artículo 3 de esta Ley, de manera que pueden constituir marcas, entre otros "las palabras o conjuntos de palabras, lemas y frases publicitarias, letras cifras, monogramas, figuras, retratos, etiquetas, escudos, estampados, viñetas, orlas, líneas y franjas y combinaciones y disposiciones de colores, sonidos, y otros signos perceptibles. Podrán asimismo consistir en la forma, presentación o acondicionamiento de los productos o de sus envases o envolturas, 0 de los medios o locales de expendio de los productos o servicios correspondientes" (sobre la reforma y adición ampliadora de este artículo para la acogida legal expresa de los signos sonoros y olfativos como signos perceptibles Bendaña-Guerrero, G.J. (20l I), Pp. 128 y 129 , que destaca cómo para algunos profesionales la reforma no resultaba estrictamente necesaria en tanto las marcas sonoras, olfativas e incluso las perceptibles por el tacto podían caber dentro de la generosa amplitud y generalidad del concepto de marca formulado por el artículo 2 de la Ley 380). Sea como fuere, debemos destacar expresamente algunas ideas.

En primer lugar, que la lista de signos que pueden potencialmente constituir marcas conforme a la normativa nicaragüense resulta meramente enunciativa y no exhaustiva o númerus clausus, como se concluye claramente de la expresión entre otros utilizada por el texto legal. En segundo lugar y con independencia de ello, la enumeración ejemplificativa de signos que pueden constituir marca realizada por la Ley centroamericana resulta realmente completa y detallada, muy prolija, de manera que contempla signos que omite y desconoce la Ley española, como los lemas y frases publicitarias, los monogramas, retratos, etiquetas, escudos y estampados o las viñetas, orlas y franjas. Los términos en los que se pronuncia la Ley nicaragüense sobre el concepto de marca resultan, por consiguiente, de una deliberada amplitud y una notoria generalidad, lo cual merece un juicio francamente favorable, pues perfilar hasta el detalle el concepto de marca o la utilización normativa de acotaciones excesivas puede llegar a plantear el acomodo de algún género de signos dentro del concepto legal de marca, todo ello en un contexto general evolutivo y mudable por esencia, en el que van apareciendo, naciendo y mutando a velocidad de vértigo nuevas modalidades de marcas nacidas para adaptarse a un escenario competitivo por naturaleza.

b) Nos parece importante destacar el hecho, en relación con lo que anteriormente avanzábamos, de que la normativa nicaragüense haya realizado recepción legal expresa de la posibilidad de que los signos perceptibles (entre ellos los olores) puedan convertirse en signos distintivos y haya dado carta de naturaleza, por consiguiente, a las comúnmente denominadas marcas olfativas, que han 
dado lugar a abundantes problemas hermenéuticos e interpretativos en el ámbito de la Unión europea y en los Ordenamientos jurídicos de los países que la integran. El Ordenamiento jurídico español carece, quizá por una excesiva cautela y por la problemática que ha rodeado todo lo concerniente a la admisibilidad y al registro de esta clase de marcas en el ámbito de la Unión europea, de una norma análoga a la nicaragüense que se pronuncie categóricamente en favor de la admisión como marca de los olores.

Debe partirse de la base de que el problema esencial que plantean esta clase de marcas es el de su encaje dentro del requisito de la susceptibilidad de representación gráfica al que alude expresamente, en sintonía con la literalidad de las directivas europeas, el artículo 4 de la Ley 17/200I. Frente a una interpretación estricta del requisito de la susceptibilidad de representación gráfica ha llegado a sostenerse que dicha exigencia puede ser satisfecha por las marcas olfativas bien mediante la correspondiente fórmula química o por la descripción escrita del aroma. No obstante, en el ámbito europeo resulta clásica la alusión a la Sentencia del Tribunal de Justicia de las Comunidades Europeas de 12 de diciembre de 2002 que, al resolver el conocido como caso Sieckmann, sentó la doctrina de la imposibilidad de representar gráficamente el signo olfativo y llegó a la conclusión de que la descripción de un olor, aun cuando sea gráfica, no resulta suficientemente clara y precisa y de que el depósito de la muestra de un olor no constituye propiamente una representación gráfica a los efectos de satisfacer el requisito exigido por la normativa comunitaria (sobre la doctrina sentada por esta Sentencia puede consultarse el valioso análisis de Fernández-Nóvoa (2004), p. 49). La normativa nicaragüense, con su amplio y extraordinariamente flexible concepto de marca en el que no se acoge la exigencia de la representación gráfica del signo en cuestión, ha podido sustraerse de toda esta problemática y su mención expresa a la aptitud de los olores para convertirse en signos distintivos puede calificarse como verdaderamente avanzada y pionera en este ámbito (sobre estas marcas olfativas en general Hernández, M. (2008). 139-163).

c) De la comparación general entre el sistema español y el centroamericano y del sistema global de ambas regulaciones cabe deducir, en tercer y último lugar, una diferencia general de tendencia y sentido. Así, en tanto que el sistema español y la evolución de su Ordenamiento jurídico han avanzado en un proceso que bien podríamos denominar de simplificación y reducción de los signos distintivos, el Ordenamiento jurídico nicaragüense aporta un sistema de protección más amplio y diversificado, valdría decir que plural, frente al dualismo hispano. Efectivamente, en España, la Ley $17 / 200$ I se limita a la regulación de las marcas y de los nombres comerciales, habiendo desaparecido de dicho Ordenamiento la modalidad residual y de protección limitada que en su Derecho histórico vino constituida por el rótulo del establecimiento.

Frente a ello, la Ley 380 , en su exhaustivo y conceptual artículo 2, alcanza a definir las denominaciones de origen (tradicionalmente excluidas de la normativa estrictamente marcaria española y deferidas a una regulación propia), los emblemas, las expresiones o señales de publicidad comercial, las indicaciones geográficas, el nombre comercial, el nombre de dominio y el rótulo como signo visible que identifica a un local comercial determinado. Esta mayor riqueza genera, naturalmente, una mayor complejidad normativa. Sin entrar a valorar en profundidad la 
oportunidad de estas diferencias y de la mayor o menor diversificación del sistema de propiedad industrial nicaragüense frente a su homólogo español sí interesa destacar que esta diversidad de planteamiento tiene como consecuencia directa y fundamental la interdisciplinariedad y amplitud normativa de la Ley 380. En España, en efecto, la existencia de una normativa específica sobre la publicidad comercial o sobre la competencia desleal implica que, sin perjuicio de algunas lógicas concomitancias o zonas de interactuación, la Ley de Marcas centre su regulación fundamental en el régimen jurídico de los signos distintivos.

En Nicaragua, por el contrario, la Ley 380 aparece impregnada y salpicada colateralmente de conceptos y nociones lindantes con la publicidad o la competencia. A mero título de ejemplo cabe citar la definición de las expresiones o señales de publicidad comercial contenida en el propio artículo 2 del texto legal, donde se las conceptúa como "toda leyenda, anuncio, lema, frase, combinación de palabras, diseño, grabado o cualquier otro medio similar, siempre que sea original y característico, que se emplee con el fin de atraer la atención de los consumidores y usuarios”.

\section{Apunte sobre la regulación de los signos distintivos notorios}

Todas la consideraciones conceptuales y el planteamiento que hemos realizado con anterioridad viene esencialmente referido a las marcas que podemos considerar habituales u ordinarias; esto es, a aquellas que no gozan de un grado de conocimiento particularmente significativo ni especialmente destacado dentro del sector pertinente de los consumidores a los que se dirigen los productos amparados por la marca. No obstante, el Derecho nicaragüense, a semejanza en este extremo de la normativa española, aunque con alguna que otra diferencia sustantiva que pretendemos exponer, acoge la regulación de los denominados signos distintivos notorios, cuestión ésta que ha suscitado tradicionalmente un gran interés y una acusada problemática en el ámbito del Derecho de la propiedad industrial, por lo que nos parece oportuno desarrollar sucesiva y respectivamente a continuación el sentido general de la normativa española y nicaragüense con el objetivo de poner de manifiesto sus diferencias de matiz más relevantes.

\section{Regulación en España}

Tal y como resume De Javier, L. en el Seminario sobre la Nueva Ley de Marcas celebrado por la Oficina Española de Patentes y Marcas los días 17 y 18 de diciembre de 200 I (De Javier, L. (200I). Pp. 4 y 5 ) el Estatuto de Propiedad Industrial de 1929, añeja norma que primitivamente reguló el Derecho de propiedad industrial español, no recogió los conceptos de marca notoria o renombrada, ni formuló expresamente una prohibición de acceso al registro de una marca novel basada en la existencia de una marca notoria o renombrada anterior. Por ello la Jurisprudencia, unas veces con mayor acierto y otras con menos, intentó otorgar una mayor protección a aquellas marcas cuya fama o renombre fuera esgrimido por sus titulares, en un proceder que fue calificado como "muy peculiar" (Fernández-Nóvoa, C. (1990). p. 126).

Dada la no positivación del concepto, el Tribunal Supremo intentó sentar una doctrina por la cual se calificaba a la marca renombrada como una indicación de procedencia, de crédito o reputación industrial, manteniendo que una marca posterior idéntica o muy semejante constituía una "falsa indicación de 
procedencia, crédito y de reputación industrial", estando por ello, incursa en la prohibición establecida en el artículo 124.13 del venerable Estatuto de la Propiedad Industrial. En consecuencia, en un primer momento histórico, la procedencia de la protección de las marcas notorias y renombradas vino de la mano de una interpretación jurisprudencial apegada a nociones clásicas y conocidas tanto del Derecho de marcas como del Derecho de la competencia, conexión y concomitancia entre conceptos de los Derechos de la competencia y de los signos distintivos que ha resultado una constante en todo el proceso de desenvolvimiento de ambos sectores del Ordenamiento jurídico mercantil (Monteagudo, M. (1993). 73-108).

La Ley 32/1988, de Marcas (sobre dicha Ley Botana, M. (1989-1990) 13-40) sólo recogió el concepto de marca notoria en su artículo. 3.2 al reconocer los derechos del titular de marca notoria, que en la práctica resultaron fundamentalmente marcas notorias extranjeras, no registrada en España y en el artículo 38.3 al disponer que se habría de tener en cuenta la "notoriedad y prestigio" de la marca para fijar la indemnización en los supuestos de violación de los derechos de su titular. Por su parte, la Ley de 1988 no recogió explícitamente el concepto de marca renombrada. La no cristalización legal de estos conceptos condujo, por consiguiente, a la inexistencia de una doctrina firme respecto al alcance de la protección de ambos signos distintivos, a lo que se añadió la reticencia jurisprudencial de una doctrina conforme a la cual "Las marcas notorias y renombradas se protegen por sí solas, dado el grado de conocimiento que de ellas tiene el público".

En cualquier caso, las reflexiones anteriores realizadas a partir de la evolución de la normativa española, y dejando para un momento posterior el tratamiento que sobre la cuestión establece la vigente Ley 17/200I de Marcas, nos sitúa ante dos conceptos emparentados aunque de contenido diverso: la notoriedad, concebida como el conocimiento de la marca por parte del sector del público consumidor al que van dirigidos los productos o servicios, y el renombre que consiga concitar la marca, sustentado en que a la totalidad o a la mayor parte de los consumidores la marca le resultará conocida y ostentará una reputación, si cabe, más elevada, por lo que estará amparada por una mayor distintividad y su poder precisamente estribará en la celebridad, resonancia y reputación de la marca, es decir en el prestigio o fama de la marca. Desde esta perspectiva, las marcas notorias serán aquellas que no trascienden del ámbito de la regla de la especialidad, en tanto que la marca renombrada es aquella que aglutina un nivel de reputación, autoridad, y estimación que hacen que su calidad y goodwill sean tan elevados que le permitan trascender aun más allá del sector del mercado siendo conocida por todos, y todos estos factores hacen que concentre el presupuesto para superar las fronteras de la regla de la especialidad.

Aclarado el concepto de marcas notorias y renombradas debe afirmarse que no existe, sin embargo, consenso generalizado a la hora de determinar cuáles son las razones que fundamentan la conveniencia de la protección reforzada de tales clases de marcas, si bien impera la consideración de que, en el fondo, se trata de razones sustentadas en su importancia económica. La marca renombrada tiene, en efecto, un alto valor económico, como resultado de su capacidad informativa en el mercado gracias a su poder de atracción entre los consumidores o destinatarios, y esa es la cuestión por la cual la marca renombrada requiere de un ámbito especial de protección, para evitar que la misma sea utilizada por terceros en el mercado, sin consentimiento del titular, debido a su valor económico que será siempre asociado a calidad, prestigio, buenos precios en algunos casos, y lugar de procedencia. 
La vigente Ley 17/200I, de Marcas, incorporó por vez primera en el Ordenamiento jurídico español una regulación sistemática de esta clase de signos distintivos notorios, la cual vino a ser considerada como una de las novedades fundamentales de dicho texto legal, frente a la ausencia de una regulación normativa o a la tangencialidad con la que ésta se había producido en las normas legales precedentes a la que acabamos de referirnos. En concreto, son los dos los preceptos de la Ley española que se refieren a la cuestión analizada:

a) El artículo 34 de la Ley española, en efecto, bajo la rúbrica Derechos conferidos por la marca y en sede del Título $V$ del texto legal regulador del contenido del derecho de la marca (Galán, E. (2003) 497) dispone que "I. El registro de la marca confiere a su titular el derecho exclusivo a utilizarla en el tráfico económico. 2. El titular de la marca registrada podrá prohibir que los terceros, sin su consentimiento, utilicen en el tráfico económico: a) Cualquier signo idéntico a la marca para productos o servicios idénticos a aquéllos para los que la marca esté registrada; b) Cualquier signo que por ser idéntico o semejante a la marca y por ser idénticos o similares los productos o servicios implique un riesgo de confusión del público; el riesgo de confusión incluye el riesgo de asociación entre el signo y la marca; c) Cualquier signo idéntico o semejante para productos o servicios que no sean similares a aquéllos para los que esté registrada la marca, cuando ésta sea notoria $o$ renombrada en España y con la utilización del signo realizada sin justa causa se pueda indicar una conexión entre dichos bienes o servicios y el titular de la marca o, en general, cuando ese uso pueda implicar un aprovechamiento indebido o un menoscabo del carácter distintivo o de la notoriedad o renombre de dicha marca registrada; 3 . Cuando se cumplan las condiciones enumeradas en el apartado anterior podrá prohibirse, en especial: a) Poner el signo en los productos o en su presentación; b) Ofrecer los productos, comercializarlos o almacenarlos con esos fines $u$ ofrecer o prestar servicios con el signo. c) Importar o exportar los productos con el signo. d) Utilizar el signo en los documentos mercantiles y la publicidad. e) Usar el signo en redes de comunicación telemáticas y como nombre de dominio. f) Poner el signo en envoltorios, embalajes, etiquetas u otros medios de identificación u ornamentación del producto o servicio, elaborarlos o prestarlos, o fabricar, confeccionar, ofrecer, comercializar, importar, exportar o almacenar cualquiera de esos medios incorporando el signo, si existe la posibilidad de que dichos medios puedan ser utilizados para realizar algún acto que conforme a las letras anteriores estaría prohibido" (en general, sobre esta cuestión en el Derecho español Massaguer, J. (200I). I43-I80).

b) Por su parte, el artículo 8, rubricado Marcas y nombres comerciales notorios y renombrados registrados, establece: “I. No podrá registrarse como marca un signo que sea idéntico o semejante a una marca o nombre comercial anteriores aunque se solicite su registro para productos o servicios que no sean similares a los protegidos por dichos signos anteriores cuando, por ser éstos notorios o renombrados en España, el uso de esa marca pueda indicar una conexión entre los productos o servicios amparados por la misma y el titular de aquellos signos o, en general, cuando ese uso, realizado sin justa causa, pueda implicar un aprovechamiento indebido o un menoscabo del carácter distintivo o de la notoriedad o renombre de dichos signos anteriores. 2. A los efectos de esta Ley, se entenderá por marca o nombre comercial notorios los que, por su volumen de ventas, duración, intensidad o alcance geográfico de su uso, valoración o prestigio alcanzado en el mercado o por cualquier otra causa, sean generalmente conocidos por el sector pertinente del público al que se destinan los productos, servicios o actividades que distinguen dicha marca o nombre comercial. La 
protección otorgada en el apartado I, cuando concurran los requisitos previstos en el mismo, alcanzará a productos, servicios o actividades de naturaleza tanto más diferente cuanto mayor sea el grado de conocimiento de la marca o nombre comercial notorios en el sector pertinente del público o en otros sectores relacionados. 3. Cuando la marca o nombre comercial sean conocidos por el público en general, se considerará que los mismos son renombrados y el alcance de la protección se extenderá a cualquier género de productos, servicios o actividades. 4. A los efectos del apartado I por marca o nombre comercial anteriores se entenderán los signos contemplados, respectivamente, en el artículo 6.2, letras a), b) y c), y en el artículo 7.2”.

Este artículo supone una de las grandes novedades de la vigente Ley española de marcas al introducir de manera expresa la ruptura del principio de especialidad por parte de los signos distintivos notorios y renombrados en el derecho positivo interno, de manera que no podrá registrarse una marca idéntica o similar a una marca notoria o renombrada aun cuando distingan productos o servicios no relacionados (ruptura del principio de especialidad), en los casos enunciados en la norma. Como una figura cualificada de la marca notoria, conocida en su sector de mercado, aparece la marca renombrada, aquella conocida por la generalidad de los consumidores, supuesto en el que, la protección resulta absoluta e impedirá el registro de signos similares con independencia de cuál sea el producto o servicio que pretenda distinguir.

De la lectura del artículo 8 de la Ley de Marcas se desprende que para su aplicación se hace necesaria la concurrencia de los siguientes requisitos:

a) Oposición previa (requisito común a todas las prohibiciones relativas). Tratándose de una prohibición relativa sólo podrá ser analizada por la Oficina Española de Patentes y Marcas a instancia de parte, es decir, sólo si el titular de la marca notoria o renombrada presenta en tiempo y forma la oportuna oposición contra una solicitud de registro de un signo distintivo.

b) Marca o nombre comercial anterior registrado o no registrado (artículos 6.2 y 7.2 de la Ley de Marcas). Los signos oponentes que se acojan a esta prohibición serán signos anteriores al solicitado, en el sentido previsto en los artículos 6.2.a), b) y c) y 7.2 de la Ley de Marcas. Es decir, tendrán la consideración de signos anteriores oponibles, las marcas nacionales o comunitarias o nombres comerciales notorios o renombrados que hayan sido solicitados o registrados con anterioridad a la fecha de presentación del signo cuya denegación se pretende. En el caso de los signos solicitados, debe cumplirse la condición de que finalmente sean concedidos.

c) Similitud de signos: Para que esta prohibición relativa sea aplicada es preciso que entre los signos en conflicto exista semejanza. Con todo ha de advertirse que la noción de semejanza que opera para los casos de marcas notorias o renombradas no es exactamente idéntica a la presente en el ámbito del juicio sobre el hipotético riesgo de confusión entre las marcas “ordinarias”, es decir que no sean notorias o renombradas.

\section{Regulación en Nicaragua}

Habiendo realizado un muy breve y sucinto apunte sobre la evolución histórica y el tratamiento de la cuestión en el Ordenamiento jurídico español procede, con el objetivo esencial de no descontextualizar al lector y apuntalar la dimensión comparativa del asunto abordado, aludir igualmente a la evolución al 
respecto de la normativa nicaragüense. El embrión de la protección marcaria en Nicaragua está constituido por una norma de la primera década del pasado siglo XX: la Ley de Marcas de Fábrica, texto legal que resultó reformado por Decreto de 30 de julio de 1926 publicado en La Gaceta Diario Oficial número 177 de 6 de agosto del mismo año. Cabe afirmar que, en parangón con el primitivo y citado Estatuto español, esta antigua norma nicaragüense tampoco formuló expresamente una prohibición de acceso al registro de una marca novel basada en la existencia de una marca notoria o renombrada anterior. Hay que esperar, por tanto, a que la vigente Ley nicaragüense establezca una regulación extensa y detallada de los signos distintivos deudora en lo esencial del Protocolo modificativo del Convenio Centroamericano para la Protección de la Propiedad Industrial para hallar un tratamiento jurídico sobre la notoriedad de los signos distintivos.

La Ley nicaragüense 380 regula esta cuestión en su capítulo XV, denominación de la notoriedad de los signos distintivos, comprensivo de los artículos 79 a 82 . En principio, y con independencia de las diferencias apreciables entre ambas regulaciones y de su valoración debe destacarse y valorarse especialmente la opción de política legislativa de la normativa nicaragüense en virtud de la cual la cuestiones relativas a los signos distintivos notorios aparecen reguladas preferentemente y con mayor extensión y detalle de manera uniforme y sistemática en este capítulo independiente pues, tal y como acabamos de poner de manifiesto, la Ley española disecciona la regulación de tales marcas en dos capítulos independientes respectivamente dedicados a la prohibiciones de registro y al contenido del derecho de marca, lo cual plantea problemas interpretativos lógicos. Aun cuando la Ley nicaragüense también aluda a la marca notoria en sede de prohibiciones relativas inserta el grueso de su regulación en un capítulo independiente. La pretendida unidad de la normativa nicaragüense debe, por consiguiente, ser expresamente enfatizada y valorada.

Más allá de esta apreciación meramente formal, la Ley 380 consagra el principio general de protección en el artículo 79, conforme al cual "un signo distintivo notoriamente conocido será protegido contra su uso no autorizado conforme a las disposiciones de este Capítulo, sin perjuicio de las demás disposiciones de esta Ley que fuesen aplicables y de las otras relativas a la protección contra la competencia desleal”. Nos parece especialmente interesante y realmente oportuna la mención expresa que realiza la norma nicaragüense acerca de la compatibilidad entre la normativa marcaria y las disposiciones relativas a la competencia desleal pues, de hecho y en numerosas ocasiones, las controversias atinentes a la utilización de marcas notorias o renombradas terminan deviniendo en asuntos en los que resulta aplicable la normativa concurrencial $y$, muy en concreto, los actos de aprovechamiento indebido de la reputación ajena. La Ley española carece de una indicación en tal sentido y quizá no hubiera estado de más, toda vez que el propio artículo 8 de la Ley introduce algunos conceptos y nociones característicos del Derecho de la competencia.

Quizás la característica esencial de la regulación centroamericana sea la delimitación, positiva y negativa, de la noción de signos distintivos notorios mediante, por una parte, el enunciado particularmente extenso y detallado de unos criterios de notoriedad (artículo 80) y, por otra parte, la enumeración de unos requisitos que no se pueden exigir para la notoriedad de un signo (artículo 8I). En el primer ámbito, el mencionado artículo 80 establece que "Para determinar la notoriedad de un signo distintivo, se tomará en consideración toda circunstancia relevante, y en particular los factores siguientes, entre 
otros: a) El grado de conocimiento del signo entre los miembros del sector pertinente dentro del país; b) La duración, amplitud y extensión geográfica de la utilización del signo, dentro o fuera del país; c) La duración, amplitud y extensión geográfica de la promoción del signo, dentro o fuera del país, incluyendo la publicidad y la presentación en ferias, exposiciones u otros eventos del establecimiento, actividad, productos o servicios a los que se aplique el signo; d) La existencia y antigüedad de cualquier registro o solicitud de registro del signo distintivo, en el país o en el extranjero; e) El ejercicio de acciones en defensa del signo distintivo, y en particular toda decisión tomada por alguna autoridad nacional o extranjera en la cual se hubiese reconocido la notoriedad del signo; y, f) El valor de toda inversión efectuada para promover el signo distintivo, o para promover el establecimiento, actividad, productos o servicios a los que se aplique el signo".

Ahora bien, como claramente se desprende del tenor de la normativa nicaragüense el enunciado de tales criterios tiene una finalidad meramente ejemplificativa y enunciativa, pues el artículo $8 \mathrm{I}$ de la Ley dispone expresamente que puede ser considerado como notorio un signo que no cumpla con los criterios anteriormente establecidos. Este precepto establece igualmente una serie de hechos concretos que no pueden erigirse como condición para reconocer la notoriedad de un signo distintivo y que son los siguientes: a) Que esté registrado o en trámite de registro, en el país o en el extranjero; b) Que haya sido usado o se esté usando en el comercio en el país o en el extranjero; c) Que sea notoriamente conocido en el extranjero, salvo cuando no fuera conocido en el país por otras razones; o, d) Que sea conocido por la generalidad del público en el país.

Finalmente, el artículo 82 de la Ley 380 contiene una delimitación de particular utilidad de los sectores pertinentes para determinar la notoriedad de los signos distintivos y establece que "se considerarán como sectores pertinentes para determinar la notoriedad de un signo distintivo los siguientes, entre otros: a) Los consumidores reales o potenciales del tipo de productos o servicios a los que se aplique el signo; b) Las personas que participan en los canales de comercialización del tipo de productos o servicios a los que se aplique el signo; $y, c)$ Los círculos empresariales que actúan en giros relativos al tipo de establecimiento, actividad, productos o servicios a los que se aplique el signo" y que para efectos de reconocer la notoriedad de un signo bastará que sea generalmente conocido dentro de alguno de los sectores pertinentes".

\section{Algunas diferencias entre ambas regulaciones}

De la confrontación de las regulaciones cuyos aspectos esenciales hemos expresado anteriormente podemos destacar, con una sucinta valoración, las siguientes diferencias:

a) La regulación de la notoriedad y del renombre en la Ley española resulta potencialmente más restrictiva en cuanto a su ámbito objetivo de aplicación dado que la Ley 17/200 I regula la marca y el nombre comercial notorios, en consonancia con la dualidad de modalidades de propiedad industrial de naturaleza distintiva previstas por la Ley española a la que anteriormente se ha hecho referencia. Por el contrario, la Ley 380 regula en su capítulo XV con mayor generalidad los signos distintivos notorios, por lo que parece evidente que la notoriedad resultará predicable de cuales 
quiera de los signos distintivos regulados por la Ley y definidos en el artículo 2 del propio texto legal.

Por consiguiente, en el Derecho nicaragüense no sólo cabe imaginar la existencia de marcas o nombres comerciales notorios sino también de denominaciones de origen, emblemas o rótulos que cuadren dentro del concepto o noción de notoriedad legalmente establecido; esto es, todo signo "conocido por el sector pertinente del público o notoriamente conocido por los círculos empresariales en el país o en el comercio internacional, independientemente de la manera $\circ$ el medio por el cual se hubiese hecho conocido", aunque debamos destacar que la notoriedad o el renombre sean conceptos que han sido alumbrados en el ámbito de la propiedad industrial en relación fundamentalmente con las marcas y, en menor medida, con los nombres comerciales. Sin embargo, nada impide su extensión, mutatis mutandi, a las restantes modalidades de signos distintivos previstas por la Ley nicaragüense.

b) De mayor interés nos parece destacar el hecho de que la Ley nicaragüense carezca de una clasificación por categorías explícita y directa entre marcas notorias y renombradas al modo en que, por el contrario, sí existe en su homóloga española o, en otros términos, que la normativa centroamericana no haya recepcionado legalmente la tipología y el nomen iuris de las marcas renombradas junto al de las marcas notorias.

Con el mayor respeto, hemos de poner de manifiesto que esta opción de política legislativa nos parece cuestionable, en tanto la clasificación entre marcas notorias y renombradas resulta realmente esencial en la materia y verdaderamente crucial y decisiva en cuanto al diseño del régimen jurídico de esta clase de signos distintivos caracterizados por la extensión de su ámbito de protección derivada de la ruptura del principio de especialidad.

En la Ley española cabe destacar que este binomio marca notoria-marca renombrada ha sido oportuna y cartesianamente establecido, lo cual facilita sobremanera la intelección de la normativa y la fijación del alcance de la protección respectiva conferida a esta clase de marcas. Por el contrario, el Derecho nicaragüense, por razones que no alcanzamos, no contempla de forma explícita y categórica la existencia de los signos distintivos renombrados. Ahora bien, y entiendo que aquí pueden radicar los problemas interpretativos esenciales planteados por la normativa nicaragüense, el hecho de que esta clasificación no haya sido expresamente establecida no impide entender que pueda considerarse implícitamente presente y consagrada de forma tácita o, en otros términos, que dentro de la calculada ambigüedad y de la flexibilidad que caracteriza el sistema nicaragüense, no resulta ilógico considerar que quepa admitir la posible existencia de signos distintivos renombrados.

Esta ausencia de consagración expresa plantea, por consiguiente, algunas dificultades interpretativas que podrían haber sido fácilmente evitadas si, como en el caso de la legislación española, se hubiera acogido legalmente de forma indubitada el nomen iuris de los signos renombrados junto con el de los signos notorios. En relación directa con este asunto está la muy tenue consagración realizada por el Ordenamiento nicaragüense del principio de especialidad de las marcas, ausente del 
concepto legal de marca enunciado por el artículo 2 de la Ley 380 que hemos analizado anteriormente y la ausencia en la Ley 380 del precepto existente en el Ordenamiento jurídico español conforme al cual la protección conferida a los signos notorios y renombrados "alcanzará a productos, servicios o actividades de naturaleza tanto más diferente cuanto mayor sea el grado de conocimiento de la marca o nombre comercial notorios en el sector pertinente del público o en otros sectores relacionados". En lugar de esta flexible norma, de extraordinaria utilidad para delimitar el alcance de la protección otorgada a las marcas notorias y renombradas, el artículo 84 de la Ley nicaragüense, al establecer la noción de uso no autorizado a los efectos de la atribución de acciones al legítimo titular de un signo distintivo notoriamente conocido establece que "constituirá uso no autorizado del signo distintivo notoriamente conocido, el uso del mismo en su totalidad o en una parte esencial, o de una reproducción, imitación, traducción o transliteración del signo susceptibles de crear confusión, en relación con establecimientos, actividades, productos o servicios idénticos o similares a los que se aplica el signo notoriamente conocido.

También constituirá uso no autorizado del signo distintivo notoriamente conocido el uso del mismo en su totalidad o en una parte esencial, o de una reproducción, imitación, traducción o transliteración del signo, aun respecto de establecimientos, actividades, productos o servicios diferentes a los que se aplica el signo notoriamente conocido, o para fines no comerciales, si tal uso pudiese causar alguno de los efectos siguientes: a) Riesgo de confusión o de asociación con el titular o legítimo poseedor del signo, o con sus establecimientos, actividades, productos o servicios. b) Daño económico o comercial injusto al titular o legítimo poseedor del signo por razón de una dilución de la fuerza distintiva o del valor comercial o publicitario del signo. c) Aprovechamiento injusto del prestigio del signo, o del renombre de su titular o legítimo poseedor". Estamos muy de acuerdo con la exégesis de este precepto realizada por Hernández Alfaro, M. cuando afirma que "existe una discordancia entre el régimen de protección de estos signos y la denominación que se emplea para definirlos, porque a través de una única figura se ha pretendido regular fenómenos jurídicos de distinta naturaleza" (en su ya citada Tesis Doctoral La registrabilidad de la marca en el Derecho nicaragüense, Hernández, M. (20/4). La registrabilidad de la marca en Derecho nicaragüense. 19 de septiembre de 2016, de Universidad de Alcalá de Henares Sitio web: http://hdl.handle.net/10017/20568, p. 244).

c) Con entera independencia de la observación crítica realizada y de la certeza de que la acogida del concepto de marca renombrada hubiera resultado realmente positiva para el Ordenamiento nicaragüense hemos de destacar que la regulación centroamericana cuenta con una enumeración frondosa y particularmente útil de los criterios para la atribución de la notoriedad que, en este concreto extremo, resulta incluso dotada de mayor coherencia y mejor sistemática que la más abigarrada y sintácticamente compacta de la norma española, aunque los criterios, sin perjuicio del mayor desarrollo que parecen alcanzar en la normativa nicaragüense, resulten sustancialmente coincidentes. De este modo, la Ley española incrusta los criterios para la atribución de la notoriedad dentro del propio concepto de marca notoria formulado por el citado artículo 8.2 del texto legal, de manera que la marca notoria es aquella que sea generalmente conocida por el sector pertinente del público al que se dirigen los productos, servicios o actividades distinguidos por la 
marca "por su volumen de ventas, duración, intensidad o alcance geográfico de su uso, valoración o prestigio alcanzado en el mercado o por cualquier otra causa”.

Ambas normativas vienen a coincidir en el criterio esencial para la atribución de la notoriedad a los signos distintivos, que no es otro que el de la duración, intensidad o amplitud geográfica del uso o utilización del signo en cuestión, pero llama poderosamente la atención que el Derecho nicaragüense, que regula la cuestión con mayor extensión y una más depurada sistemática que la Ley española, dedicando a la enumeración de los criterios un precepto independiente y sin incrustar la fijación de dichos criterios en el propio concepto de los signos distintivos notorios, omita, sin embargo, alguno de los criterios a los que alude la más escueta y simplificada normativa española. No alude, por ejemplo, el artículo 80 de la Ley 380 al volumen de ventas explícitamente mencionado por la Ley española, lo cual choca más en tanto que sí considera el Ordenamiento centroamericano criterio para la determinación de la notoriedad las circunstancias que rodean a la promoción del signo (se mencionan la duración, amplitud y extensión geográfica de dicha promoción), con lo que podemos llegar a la anómala conclusión de que el Ordenamiento nicaragüense prioriza más en orden a la determinación de la notoriedad de la marca la promoción que la propia comercialización de los productos amparados por la marca.

Tampoco menciona el Ordenamiento nicaragüense como criterio la valoración o prestigio alcanzados en el mercado por el signo notorio a los que alude la norma hispana, si bien este caso la omisión bien puede deberse a la circunstancia de que la elevada valoración y prestigio suelen venir asociados al goodwill o elevada reputación o renombre y tales nociones se vinculan ordinariamente a las marcas renombradas, concepto que, como hemos puesto anteriormente de manifiesto no acoge legalmente la Ley nicaragüense.

En sentido inverso, dicha Ley menciona otros criterios que pasa por alto, sin embargo, la Ley española y es de justicia reconocer que pueden presentar un elevado valor indiciario en orden a la atribución de la notoriedad, como la publicidad y presentación en ferias, exposiciones u otros eventos, la antigüedad de los registros o solicitud de registros de los signos distintivos en cuestión o el ejercicio de acciones o la existencia de decisiones previas de autoridades nacionales o extranjeras en las que hubiera podido reconocerse la notoriedad del signo en cuestión. Aun cuando la naturaleza de la enumeración de estos criterios resulte meramente enunciativa y no exhaustiva nos parece encomiable la prolijidad y el esfuerzo constructivo de ordenación que la norma nicaragüense destina al particular y que resulta bastante más prolija y sistemática que la lacónica referencia tangencial, y al hilo del concepto, de la Ley española.

Ahora bien, ello advertido, esta elogiable fijación de criterios del artículo 80 de la Ley 380 consideramos que queda ensombrecida, en parte, por la más confusa y, permítasenos la expresión, desafortunada norma del artículo $8 \mathrm{I}$ de la Ley 380, que al enumerar los "requisitos que no se pueden exigir para la notoriedad de un signo" declara que en ningún caso será condición para reconocer la notoriedad de un signo distintivo "que haya sido usado o se esté usando en el comercio en el país o en el extranjero", de manera que en preceptos sucesivos de la Ley 380 viene a afirmarse una cosa y su contraria. El artículo 80 declara que la duración, amplitud e intensidad del uso pueden resultar criterios válidos (y de hecho lo son en la práctica generalidad de los casos) para la determinación de la notoriedad y el artículo $8 \mathrm{I}$ declara que no puede ser condición para reconocer la notoriedad del signo. Este artículo 81 conduce 
por tanto a conclusiones difíciles de asumir desde el punto de vista del Derecho de marcas pues la notoriedad suele venir habitualmente de la mano del uso, y el hecho de que los signos sean generalmente conocidos por el sector pertinente del público al que se dirigen los productos o servicios (los consumidores reales o potenciales del tipo de productos o servicios a los que se aplica el signo en expresión del Derecho nicaragüense) suele ser una consecuencia directa de la utilización habitual, constante y sostenida de dicho signo en el tráfico. Consideramos, por consiguiente, que este artículo $8 \mathrm{I}$ no aporta demasiado a la elegante formulación positiva de criterios para la delimitación de la notoriedad realizada en el artículo 80; antes bien, plantea cierta confusión interpretativa y algunas dudas justificadas en cuanto a su contenido.

\section{La regulación de las prohibiciones de registro}

\section{Presupuesto}

El Derecho de Marcas ha distinguido tradicionalmente dentro de las prohibiciones de registro de los signos distintivos entre las denominadas prohibiciones absolutas y las prohibiciones relativas, clasificación que, si bien con terminología dispar como tendremos ocasión de exponer seguidamente, siguen tanto la Ley nicaragüense como la española. Ambas clases de prohibiciones hallan su diferencia esencial en su respectivo fundamento; así, mientras que las prohibiciones absolutas se asientan sobre la legítima aspiración de preservar el interés público o general evitando monopolios injustificados que mermen la libertad concurrencial en el mercado, las prohibiciones relativas satisfacen un interés meramente particular o privado, en tanto aspiran simplemente a tutelar derechos de terceros derivados en la generalidad de los casos de un registro anterior. Desde esta óptica, las prohibiciones relativas entroncan, en cierta medida, con los principios jurídicos clásicos de prioridad temporal, con el viejo prior tempore, potior iure, dado que conceden al titular del signo distintivo que acceda al Registro con anterioridad un derecho de preferencia y de oposición en relación con signos análogos que pretendan acceder al registro con posterioridad.

Esta diferencia en cuanto al fundamento respectivo de las prohibiciones absolutas y relativas implica que, en el primero de los casos, el signo distintivo cuyo registro se prohíbe presenta un defecto que bien podríamos denominar endógeno, constitutivo o intrínseco (muy expresivamente a nuestro juicio el artículo 7 de la Ley nicaragüense 380 se refiere a las marcas inadmisibles por razones intrínsecas) mientras que en el segundo de los supuestos la conformación de la marca resulta teóricamente válida o idónea, no intrínsecamente viciada, pero agrede derechos de terceros derivados de anterioridades registrales. En las páginas siguientes vamos a sintetizar brevemente el régimen respectivo de esta clase de prohibiciones en las normativas nicaragüense y española y a reseñar sus analogías, sin perjuicio de destacar sus diferencias de matiz más apreciables.

\section{Prohibiciones absolutas o fundamentadas en razones intrínsecas}

Los artículos 5 de la Ley española (prohibiciones absolutas) y 7 de la Ley 380 (marcas inadmisibles por razones intrínsecas) regulan de manera particularmente exhaustiva y detallada esta clase de prohibiciones, más si cabe en la normativa centroamericana, en la cual el número de prohibiciones 
establecidas excede mínimamente del de las previstas por la norma española. Fernández-Nóvoa (2004, p. 155) ha puesto de manifiesto que a la hora de aplicar las prohibiciones absolutas suelen plantearse delicados problemas de deslinde y hasta qué punto suele resultar problemático delimitar el ámbito respectivo de las prohibiciones. A continuación, y habida cuenta la longitud de los preceptos que regulan esta cuestión, vamos a exponer sucesivamente con un sucinto comentario las prohibiciones compartidas por ambas normativas, dejando para el final las alusión a aquellas que solo son previstas en una de las dos leyes marcarias.

Como prohibiciones intrínsecas o absolutas mencionadas por ambas normas cabe destacar las siguientes:

a) Los signos que carezcan de aptitud o carácter distintivo: Ambas leyes contemplan esta prohibición si bien en términos no estricta ni literalmente coincidentes. La Ley española se refiere, sin más, a los signos "que carezcan de carácter distintivo", mientras que la Ley nicaragüense alude con mayor desarrollo a los signos que evidencien "carecer de suficiente aptitud distintiva con respecto al producto o servicio al cual se aplique". En cualquier caso, esta prohibición, desconocida en la Ley de marcas española de 1988, fue introducida en la vigente Ley de 200 I por razones de convergencia con la prohibición estrictamente idéntica prevista por el artículo 3.I.b) de la Directiva 89/104 y vino a constituir "un novum en el Derecho español de Marcas" (Fernández-Nóvoa (2004), p. I72).

El fundamento de esta prohibición resulta más que evidente y entronca con el propio concepto de marca formulado por la legislación nicaragüense en su artículo 2 que hemos tenido ocasión de exponer y que la configura como el signo apto de por sí para distinguir productos o servicios, de manera que la fuerza distintiva se configura como el elemento esencial sobre el que descansa toda la arquitectura conceptual del Derecho de marcas, de manera que su ausencia determina la propia inexistencia de la marca. Ahora bien, en sede de esta prohibición cabe destacar una importante diferencia entre las normativas española y nicaragüense que lleva a interpretar que la prohibición ha sido establecida en términos más estrictos por esta última. La Ley española, en efecto, permite soslayar la prohibición cuando la marca hubiera adquirido para los productos o servicios para los cuales se solicita su registro carácter distintivo como consecuencia del uso que de ella se hubiera realizado (artículo 5.2 de la Ley 17/200I), posibilidad que, por el contrario, no permite la Ley 380, en la que la prohibición, por consiguiente, ha sido establecida en términos categóricos y no excepcionales.

b) Los signos contrarios a la Ley, al orden público o a la moral: También ambas leyes marcarias comparten esta prohibición intrínseca o absoluta, sin otra mínima diferencia de matiz que la referencia de la norma nicaragüense a la noción de moral frente a la utilización por la Ley española del concepto de buenas costumbres, si bien se trata de conceptos realmente concomitantes en tanto que las buenas costumbres han sido asimiladas a "la conducta moral exigible y exigida en la normal convivencia de las personas estimadas honestas” (Fernández-Nóvoa, C. (2004), p. 23I). Esta ausencia de la norma nicaragüense del concepto de buenas costumbres resulta, por cierto, especialmente llamativa porque esta noción era empleada por el Convenio Centroamericano para la Protección de la Propiedad Industrial cuyo artículo 10.g) aludía a los efectos de esta prohibición a los signos, palabras o expresiones contrarias a la moral, el orden público o las buenas costumbres. 
Sea como fuere, esta prohibición aspira a preservar el conjunto de principios jurídicos, políticos, éticos y de orden social sobre los que se sustenta la convivencia y que suelen cristalizar en normas de ius cogens o derecho obligatorio.

c) Los signos consistentes en formas prohibidas expresamente por la Ley: Bajo esta denominación genérica hemos aglutinado diferentes supuestos que, en términos relativamente coincidentes aunque con algunas variaciones léxicas, regulan tanto la Ley española como la nicaragüense. El artículo 5. I.e) de la primera de dichas leyes impide el registro como marca en tal concepto de los signos constituidos exclusivamente por "la forma impuesta por la naturaleza del producto o por la forma del producto necesaria para obtener un resultado técnico, o por la forma que da un valor sustancial al producto". Por su parte, la Ley 380 disecciona estos casos que la Ley española contempla de forma conjunta, con una sistemática que, en este apartado concreto, consideramos que contribuye a la mejor delimitación de los supuestos contemplados. La letra c) del artículo 7 de esta Ley declara inadmisible el registro de "la forma usual o corriente del producto al cual se aplique o de su envase o acondicionamiento" y "la forma necesaria o impuesta por la naturaleza del producto o servicio de que se trate". Por su parte, la letra d) del mismo artículo cierra el registro a los signos que "consistan en un forma o signo que dé una ventaja funcional o técnica al producto o servicio al cual se aplica".

Intentando sintetizar de manera clara la redacción relativamente compleja de estas normas encontramos que se engloban y yuxtaponen, fundamentalmente, dos prohibiciones concretas. En primer lugar la referida a la forma impuesta por la naturaleza del producto. La Ley nicaragüense realiza en este punto una precisa acotación que contribuye a la delimitación conceptual del supuesto, en tanto alude a la forma "necesaria". Tal y como declara Fernández-Nóvoa (2004, p. 221 ) el fundamento de esta prohibición resulta obvio, pues "se trata de evitar que por la vía del derecho exclusivo sobre la marca una persona obtenga un monopolio temporalmente ilimitado sobre el producto cubierto por la solicitud de la marca", si bien debe destacarse que no se trata de una prohibición que presente una frecuencia particularmente elevada en cuanto a su estimación en la práctica. En segundo lugar, también con diferente tenor literal, las dos normativas analizadas impiden el registro como marcas de la forma o signo que dé una ventaja funcional o técnica al producto o servicio de que se trate, prohibición con la que se aspira a delimitar y a deslindar adecuadamente los cauces de protección que, en materia de propiedad industrial, brindan respectivamente la normativa sobre signos distintivos y la atinente a las denominadas creaciones industriales; normativa que ha merecido en España una reforma en profundidad operada por la reciente Ley 24/20I5, de 24 de julio, de Patentes (Barrero, E. (2016). Hacia un nuevo régimen jurídico de la creación industrial. Madrid: Marcial Pons).

d) Los signos usuales o habituales: La letra d) del artículo 5.I de la Ley española cierra el registro a aquellos signos que "se hayan convertido en habituales para designar los productos o los servicios en el lenguaje común o en las costumbres leales y constantes del comercio" y, en sentido análogo, la Ley 380 declara inadmisible el registro de la marca que "consista exclusivamente en un signo usual o una indicación que, en el lenguaje común o técnico, sea utilizado para designar el producto o servicio al cual se aplica”. 
También en este caso el fundamento de la prohibición entronca con la más esencial de las funciones de la marca como es su aptitud distintiva de los productos o servicios dado que, en último término, la habitualidad del signo en el lenguaje común o en el comercial es la que le priva, en suma, de potencialidad distintiva. Bajo esta obligación se ha englobado tradicionalmente la inadmisibilidad de las denominadas marcas genéricas, es decir de aquellas cuyo signo consiste exclusivamente en la designación del género de los productos o servicios a los que se aplica pero hemos de destacar que la prohibición abarca igualmente otros supuestos y que la tendencia doctrinal viene a ser la de una interpretación flexible y amplia sobre su contenido de manera que (Fernández-Nóvoa (2004), p. 202) "la prohibición analizada es extensible a las locuciones habitualmente utilizadas en la publicidad y promoción de los productos y servicios cubiertos por la correspondiente marca".

Nos parece igualmente oportuno realizar una precisión y destacar que signo usual o habitual no es estrictamente sinónimo de signo coloquial o de amplia difusión, en tanto que se prohíben no sólo aquellos signos habituales en el lenguaje común, sino en el ámbito específico, y potencialmente más restringido, de las costumbre leales o constantes del comercio (lenguaje común o técnico, como declara expresivamente la Ley nicaragüense). Por último, debe destacarse que esta prohibición debe resultar restrictivamente interpretada conforma a la enfatización adverbial exclusivamente que comparten tanto la Ley española como la nicaragüense, de manera que cabe sostener que se prohíben las marcas exclusivamente usuales o habituales pero que la prohibición puede resultar salvada cuando se adicione o incorpore a la marca algún elemento que le atribuya la elemental capacidad distintiva que permita su acceso al registro.

e) Los signos descriptivos: Constituye una prohibición compartida por ambas leyes si bien, en este caso concreto, consideramos que la Ley 380 regula esta cuestión concreta de una manera más parca y lacónica que su homóloga española. En efecto, la letra c) del artículo 5 . I de la Ley española declara que no pueden registrarse como marca los signos "que se compongan exclusivamente de signos o indicaciones que puedan servir en el comercio para designar la especie, la calidad, la cantidad, el

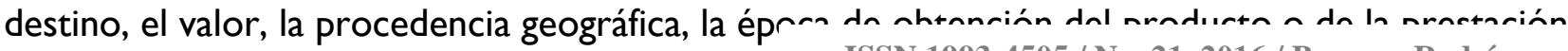
del servicio u otras características del producto

La enumeración ejemplificativa que realiza la norma española resulta en este extremo particular más amplio y generoso que la formulación de la prohibición en la Ley 380 que, más abreviadamente, declara inadmisible las marcas que consistan en "un signo que designe, o describa o califique las características, cualidades u otros datos correspondientes al producto o servicio que pretende identificar. La diferencia esencial radica, por consiguiente, en que mientras que la norma española realiza una enumeración exhaustiva de extremos concretos en los que puede verificarse la descriptividad de la marca la Ley nicaragüense opta por no descender a dicha enumeración, y utiliza la expresión genérica de "otros datos". La prohibición de las marcas descriptivas cuentas con una larga tradición en el Derecho europeo de marcas y fue contemplada por el artículo 3 de la Directiva 89/104/CEE, que inspira claramente el contenido de la norma española antes citada. La prohibición se apoya, en definitiva, en la carencia de naturaleza distintiva de los signos descriptivos y en la necesidad de mantener libremente disponibles tales signos a fin de que puedan ser utilizados por todos los empresarios que operan en el correspondiente sector del mercado (Fernández-Nóvoa (2004), p. 186). 
f) Los signos engañosos: También comparten ambas normativas la prohibición de registro absoluta o intrínseca de los signos engañosos, si bien con algún matiz diferencial en cuanto a la terminología respectivamente empleada. De este modo, la letra g) del artículo 5.1 de la Ley española impide el registro como marca de los signos "que puedan inducir al público a error, por ejemplo, sobre la naturaleza, la calidad o la procedencia geográfica del producto o servicio”. Más que en la motivación subjetiva del ánimo de engaño la norma prioriza, por consiguiente, el resultado objetivo del error padecido por el consumidor aun cuando, naturalmente dicho resultado suela provenir de aquélla.

Esta prohibición se fundamenta en las exigencias de veracidad y transparencia del mercado y en la necesidad de preservar el correcto cumplimiento de la función informativa de la marca; se trata, en definitiva, de proteger el correcto funcionamiento del mercado, en el que la ley de la oferta y la demanda cumple una función trascendente, ante la posibilidad de que los consumidores, en el momento de tomar la decisión de adquirir o no los bienes, productos o servicios, estén errados sobre la características de los mismos que puedan influir en aquélla. De hecho, la tipificación general de los actos de engaño ha tenido lugar habitualmente en sede de la normativa sobre competencia desleal, por lo que en este ámbito concreto vuelve a evidenciarse la concomitancia entre los sectores del Derecho de la competencia y del Derecho de la propiedad industrial a la que hemos aludido ya en alguna ocasión en este estudio. La Ley nicaragüense, por parte, declara la inadmisibilidad de registro de "los signos susceptibles de crear confusión o engaño sobre la procedencia geográfica, la naturaleza, el modo de fabricación, las cualidades, la aptitud para el empleo o consumo, la cantidad o alguna otra característica del producto o servicio al cual se aplica". La redacción de este precepto resulta más amplia que la de la Ley española en cuanto a la enumeración de los extremos concretos en los que cabe apreciar la confusión o el engaño padecidos por el consumidor, dado que se añaden a la naturaleza, la calidad o la procedencia geográfica del producto (únicos extremos que cita la Ley española) cuestiones tales como la cantidad, el modo de fabricación o la aptitud para el empleo o consumo del producto.

En cualquier caso interesa destacar que el error, confusión o engaño pueden producirse sobre cualquier otro aspecto, dado que la enumeración resulta meramente ejemplificativa, como resulta de las expresiones por ejemplo y alguna otra característica empleadas respectivamente por las normas española y nicaragüense. No obstante, hemos de destacar expresamente que la redacción de la Ley nicaragüense plantea algún nrnhloma do dalimitarión y deslinde por la distorsionante y algo equívoca alusión a la confusió entre signos distintivos y qu oner el contraste y referencia comparativa ámbito de las prohibiciones relativas.

g) Los signos revestidos de oficialidad o naturaleza pública: de manera que bien podríamos calificar como residual las leyes nicaragüense y española consagran determinadas prohibiciones que tienen su fundamento en razones de interés público y en la consiguiente conveniencia de mantener el alto valor simbólico de determinados símbolos y emblemas. En concreto, las letras k), I) y n) del artículo 7 de la Ley 380 declaran la inadmisibilidad de registro por razones intrínsecas de los signos que constituyan una reproducción o imitación, total o parcial, de un escudo, bandera u otro emblema, sigla, denominación o abreviación de denominación de cualquier Estado u organización internacional, sin autorización del Estado o de la organización internacional de que se trate, los 
que incluyan una reproducción o imitación, total o parcial, de un signo oficial o de un signo de control o de garantía de un Estado o de una entidad pública nacional o extranjera, departamental, provincial o municipal, sin autorización de la autoridad competente $y$, en fin, los que reproduzcan monedas o billetes de curso legal en el territorio de cualquier país, títulos-valores u otros documentos mercantiles, sellos, estampillas, timbres o especies fiscales en general. Por su parte, la Ley española de marcas subsume en esta prohibición los tres últimos supuestos de prohibiciones absolutas que enumera en las letras i), j) y k) de su artículo 5.I, que abarcan, respectivamente, los signos que reproduzcan o imiten el escudo, la bandera, las condecoraciones y otros emblemas de España, sus Comunidades Autónomas, sus municipios, provincias u otras entidades locales (a menos que medie la debida autorización), los que no hayan sido autorizados por las autoridades competentes y deban ser denegados en virtud del artículo 6 ter del Convenio de París y los que incluyan insignias, emblemas o escudos distintos de los contemplados en el artículo 6 ter del Convenio de París y que sean de interés público, salvo que su registro sea autorizado por la autoridad competente.

Sin perjuicio de la existencia de este grupo de prohibiciones absolutas que resultan, si bien con ligeras variaciones, compartidas por la normativa española y centroamericana, ambas leyes contienen algunas prohibiciones específicas y concretas que solo se enuncian en sus respectivos Ordenamientos y de las que vamos a dar cuenta breve y sucinta para concluir este análisis de las prohibiciones absolutas.

La Ley española 17/200 I formula las siguientes prohibiciones absolutas no contempladas por la normativa nicaragüense:

a) En primer lugar, el artículo 5.I.a) declara la imposibilidad del registro como marca de los signos que "no puedan constituir marca por no ser conformes al artículo 4.I de la presente Ley", Se trata, en suma, de una norma que procura la convergencia con el concepto de marca previsto por la normativa española al que hemos tenido ocasión de referirnos y en el que destaca sobremanera la exigencia de la susceptibilidad de representación gráfica como requisito básico para la existencia de la marca.

Por tanto, tal y como ha puesto de manifiesto la mejor doctrina (Fernández-Nóvoa (2004), p. 160) esta prohibición abarca dos tipos de signos: "en primer término, los signos no susceptibles de representación gráfica, $y$ en segundo término, los los productos o servicios de una empresa de los

ISSN 1993-4505 / No. 21, 2016 / Barrero Rodríguez

El Ordenamiento jurídico nicaragüense carece de una prohibición análoga tal, opción que debe reputarse extraordinariamente lógica y razonable porque, al carecer la Ley centroamericana de la exigencia de la representación gráfica como requisito constitutivo de la marca y ser particularmente flexible en cuanto a la admisión como marca de los signos perceptibles (incluyendo los olfativos) no hubiera tenido sentido la instauración de una norma de este tenor. Debe añadirse a ello que los supuestos que en la normativa española pudieran caer dentro del ámbito de aplicación de esta prohibición pueden quedar fácilmente subsumidos en el Derecho nicaragüense en el apartado prohibitivo de la carencia de suficiente aptitud distintiva del signo con respecto al producto o servicio al que el signo resulta de aplicación. 
b) En segundo lugar, la letra h) del artículo $5 . I$ de la Ley española contiene una prohibición de la que carece la normativa nicaragüense, si bien dicha afirmación debe ser matizada. Conforme a ella no pueden registrarse como marcas en España los signos que "aplicados a identificar vinos o bebidas espirituosas contengan o consistan en indicaciones de procedencia geográfica que identifiquen vinos o bebidas espirituosas que no tengan esa procedencia, incluso cuando se indique el verdadero origen del producto o se utilice la indicación geográfica traducida o acompañada de expresiones tales como clase, tipo, estilo, imitación u otras análogas".

Dentro de la extensa redacción de esta norma cabe, por consiguiente, distinguir dos supuestos, la solicitud de una marca consistente en una indicación geográfica de vinos o bebidas espirituosas para designar este género de bebidas cuando no procedan de dicha zona geográfica (esto es, la utilización de forma falsaria de la indicación geográfica) y la utilización de la indicación, aun sin ocultar el verdadero origen del producto, acompañada de expresiones matizadoras como tipo, clase, estilo u otras análogas, si bien en el primer supuesto quizás la previsión resulte ociosa porque, como hemos visto, la Ley establece la prohibición absoluta de registro de los signos engañosos que puedan inducir a error sobre la procedencia geográfica del producto o servicio.

En suma, frente a la generalidad con la que están previstas la totalidad de las prohibiciones absolutas contempladas por la Ley española, este precepto incorpora una previsión singularizada para un supuesto concreto caracterizado por su especificidad y únicamente aplicable, en consecuencia, a las indicaciones de procedencia geográfica aplicadas a identificar vinos o bebidas espirituosas. La normativa nicaragüense carece de una norma tal; esto es, de una referencia singularizada y concreta a las indicaciones geográficas destinadas a vinos o bebidas espirituosas, aun cuando sí contenga, por el contrario, la consagración de una prohibición genérica referida a las indicaciones geográficas.

En efecto, conforme a la letra j) del artículo 7 de la Ley 380 no resulta admisible el registro como marca de un signo consistente en una indicación geográfica que no se ajuste a lo dispuesto en el párrafo segundo del artículo 3 de la Ley, precepto que tras la redacción otorgada por la Ley 580/2006 de reformas y adiciones a la Ley de marcas 380 dispone que "una marca será susceptible de constituir una indicación geográfica nacional o extranjera, siempre que distinga los productos o servicios a los cuales se aplique, y que su empleo no sea susceptible de c? cualidades o características de los pr probabilidad de confusión con una ir ón con respecto al origen, procedencia, s cuales se aplicará la marca, ni una productos o servicios, o un aprovechamiento injusto del prestigio de esa indicación geográfica."

Por su parte, la letra $\mathrm{m}$ ) del artículo 7 de la Ley 380 contempla un supuesto de prohibición por razones intrínsecas que no resulta previsto en la Ley de Marcas española, quizás porque su previsión concreta bien podría haber sido deferida a la normativa especial y sectorial reguladora de esta clase de propiedad especial que son las obtenciones vegetales. En virtud de dicho precepto se declara inadmisible el registro como marca de los signos que consistan en una "denominación de una variedad vegetal protegida como tal en el país o en el extranjero, si el signo se destinara a productos o servicios relativos a esa variedad o su uso sería susceptible de causar confusión o asociación con ella”. 
La ubicación de esta prohibición en el apartado de prohibiciones intrínsecas suscita, por lo demás, cierta extrañeza interpretativa porque, viéndose en el supuesto comprometidos los derechos de los terceros y eventuales titulares de la obtención vegetal, lo más lógico hubiera sido su inclusión dentro de las prohibiciones inadmisibles por derechos de terceros previstas en el siguiente precepto, de ahí que la doctrina nicaragüense haya podido afirmar con todo fundamento (Hernández, M. (2014) La registrabilidad de la marca en Derecho nicaragüense. 19 de septiembre de 2016, recuperado en Universidad de Alcalá de Henares Sitio web: http://hdl.handle.net//0017/20568), pp. 367-368) que "la norma contenida en la letra $\mathrm{m}$ ) no se corresponde con un motivo absoluto de registro, es decir, la denominación de la obtención vegetal no es irregistrable porque carezca en si misma de la aptitud necesaria para cumplir con la función distintiva exigida a una marca sino, más bien, en este caso lo que motiva la irregistrabilidad del signo es su indisponibilidad, por lo que si se consintiese su registro se estaría vulnerando el derecho anterior reconocido a un tercero (obtentor de la variedad vegetal). En consecuencia, esta norma no debería hacer parte de las prohibiciones de registro reguladas por el artículo 7 LNM, sino más bien el legislador nicaragüense tendría que haberla incluido en el artículo 8 LNM Marcas Inadmisibles por Derechos de Terceros".

\section{Prohibiciones relativas o fundamentadas en derechos de terceros}

Los artículos 8 de la Ley 380 y 6 a 10 de la Ley de marcas española regulan las prohibiciones relativas que presentan el denominador común, frente a las intrínsecas o absolutas, de la afectación de prioridades o derechos de terceros. A continuación vamos a exponer dichas prohibiciones partiendo esencialmente de la regulación nicaragüense, sin perjuicio de algunas referencias incidentales y ocasionales a la legislación española cuando la analogía o diferencia de matiz de las regulaciones lo requiera. A tales efectos, cabe distinguir dos grandes grupos de prohibiciones: aquellas que se fundamentan en la protección de derechos de terceros no estrictamente relacionados con la propiedad industrial y las que tienen su justificación en la tutela de signos distintivos anteriores.

Dentro del primer grupo cabe destacar las siguientes:

a) Los signos que afecten al nombre o a los signos distintivos de la personalidad: la letra e) del artículo 8 de la Ley 380 entiende afectado el derecho de un tercero y, en consecuencia, inadmisible el registro de la marca en el caso de que "el signo afectara el derecho de la personalidad de un tercero, en especial tratándose del nombre, firma, título, hipocorístico, seudónimo, imagen o retrato de una persona distinta de la que solicita ।

ISSN 1993-4505 / No. 21, 2016 / Barrero Rodríguez de esa persona o, si hubiese fallecido, el de quienes mueran uecrarauos sus nereueros .

El fundamento de esta prohibición radica, naturalmente, en la protección de derechos que suelen tener en la mayoría de los Ordenamientos un fundamento político o constitucional, como es el caso de España, donde el artículo 18 de la Constitución española garantiza los derechos al honor, intimidad personal y familiar y a la propia imagen. La norma nicaragüense resulta más extensa y detallada que su homóloga española, dado que incluye extremos como la firma, título, hipocorístico o retrato a los que no alude esta última. El artículo 9.1.a) y b) de la Ley I7/200I declara, en efecto, que no podrán registrarse como marcas el nombre civil o la imagen que identifique a una persona distinta del solicitante de la marca ni el nombre, apellido, seudónimo o cualquier otro signo que para la generalidad del público identifique a una persona distinta del solicitante. 
En cualquier caso conviene destacar que tanto en España como en Nicaragua esta prohibición puede ser salvada en aquellos casos en los que exista autorización (según la Ley española) o consentimiento expreso (conforme a la nicaragüense) de la persona afectada. A esta protección del nombre de las personas físicas o naturales la Ley 380 ha añadido en el apartado f) una prohibición anómala y que suscita mayor extrañeza por la relativa imprecisión con la que se formula, la de los signos que afecten "el derecho al nombre, a la imagen o al prestigio de una persona jurídica o de una comunidad local, regional o nacional, salvo que se acredite el consentimiento expreso de la autoridad competente de esa persona o comunidad". Por lo pronto, el precepto regula unitariamente dos realidades bien distintas, el nombre e imagen de las personas jurídicas y las comunidades nacionales regionales o locales $y$, en segundo término, presenta cierta indeterminación en los conceptos que emplea. Consideramos que en este punto concreto resulta más acertadamente formulada la prohibición asimilable del Ordenamiento jurídico español referida a la "denominación o razón social de una persona jurídica que antes de la fecha de presentación o prioridad de la marca solicitada identifique en el tráfico económico a una persona distinta del solicitante, si, por ser idéntica o semejante a estos signos y por ser idéntico o similar su ámbito de aplicación, existe un riesgo de confusión en el público" (artículo 9.I.d).

b) Los signos que resulten contrarios a un derecho de autor: Esta prohibición, formulada en el artículo 8.h) de la Ley 380, impide el registro de marcas vulneradoras de los derechos de terceros derivados de la denominada propiedad intelectual, supuestos que pueden resultar potencialmente numerosos, dado que las creaciones literarias, las obras artísticas e incluso el título de las obras resultan susceptibles de convertirse en marcas (Fernández-Nóvoa, 2014, p. 256). La norma centroamericana alude genéricamente a la contrariedad del signo con "un derecho de autor". El artículo 9.I.c) de la Ley española 17/200I alude con mayor detalle a "los signos que reproduzcan, imiten o transformen creaciones protegidas por un derecho de autor" y explicita de este modo con mayor concreción el potencial elenco de conductas que pueden resultar vulneradoras de los derechos de autor en el ámbito marcario y que pueden consistir, alternativamente, en la reproducción, imitación o transformación de la obra amparada por el derecho intelectual a cuya protección se aspira.

Dentro del segundo grupo (aquel propiedad industrial de los tercer supuestos: y preferencias derivan de derechos de dos) podemos englobar los siguientes

a) Identidad del signo solicitado con una marca registrada o en trámite de registro anterior que distingue los mismos productos o servicios: la letra a) del artículo 8 de la Ley 380 contempla, por consiguiente, la hipótesis de la doble identidad, que constituye el supuesto en el que cabe apreciar una agresión más explícita y directamente constatable a los derechos de terceros adquiridos con anterioridad, de ahí que la doctrina (Fernández-Nóvoa, C. (2004), p. 243) afirme que con esta prohibición "se aspira a defender eficazmente una marca anterior frente a los conflictos más flagrantes con una marca posteriormente solicitada o utilizada por un tercero".

Se trata de los casos en los que resulta más evidente la apreciación de las circunstancias de la prohibición y se esquivan las dificultades interpretativas existentes cuando resulta necesario valorar 
la existencia de los riesgos de confusión y asociación. El artículo 6. I a) de la Ley española contempla igualmente esta prohibición, sin otro diferencia respecto de la legislación nicaragüense que aludir a productos o servicios idénticos donde la norma centroamericana se refiere a "los mismos productos o servicios". Esta exigencia de la doble identidad precisa, naturalmente, del juicio comparativo entre los respectivos signos distintivos y los productos o servicios correspondientes, planteándose la duda de si la noción de identidad debe ser interpretada en un sentido flexible y extensivo o, por el contrario, estricto y restringido. Esta última parece ser la interpretación predominante en el ámbito europeo en la jurisprudencia del Tribunal de Justicia de la Unión Europea que afirma por ejemplo, en Sentencia de 20 de marzo de 2003, que "el criterio de la identidad del signo y de la marca debe ser objeto de interpretaciones restrictivas. En efecto, la propia definición del concepto de identidad implica que los dos elementos comparados sean iguales en todos los aspectos".

b) Identidad o semejanza con una marca registrada o en trámite de registro anterior que distinga los mismos o diferentes productos o servicios si el uso pudiera provocar un riesgo de confusión o asociación con dicha marca: estos supuestos, contemplados en el artículo 8.b) de la Ley nicaragüense y 6.I.b) de la Ley de marcas española constituyen los que revisten mayor complejidad teórica, en tanto que obligan al doble juicio comparativo entre los signos para valorar su grado de similitud o semejanza y entre los productos o servicios distinguidos para determinar en qué medida resulta apreciable el riesgo de confusión erigido en elemento principal para determinar la viabilidad o inviabilidad del registro de la marca. Cabe destacar que dicho juicio resultará eminentemente casuístico, pues no resultará idéntica la labor en el caso de la comparación entre marcas denominativas simples (supuesto en el que debe tenerse presente la visión de conjunto de la marca sin descomponer su unidad) que en las hipótesis de comparación de marcas gráficas o mixtas. En cualquier caso, el elemento crucial de esta prohibición viene constituido por la existencia del riesgo de confusión, que deberá fundamentarse en una visión conjunta que atienda a la similitud o semejanza de los signos desde los ángulos gráfico, fonético y conceptual.

c) Identidad o semejanza con un nombre comercial, rótulo o emblema perteneciente a un tercero desde una fecha anterior si el uso de la marca solicitada podría causar riesgo de confusión con dicho nombre comercial, rótulo o emblema. El artículo 8.c) de la Ley 380 contempla un supuesto sustancialmente análogo al anterior pero referido, en este caso, a las restantes modalidades de signos distintivos reguladas en el propio texto legal diferentes de la marca, es decir los nombres comerciales, rótulos y emblemas, signos distintivos que resultan definidos en el artículo 2 del texto legal. La protección de los derechos de terceros derivada de la propiedad industrial resulta, de este modo, más amplia y extensa que la prevista en la normativa española en la misma medida en la que Derecho nicaragüense abarca un mosai ISSN 1993-4505 / No. 21, 2016 / Barrero Rodríguez

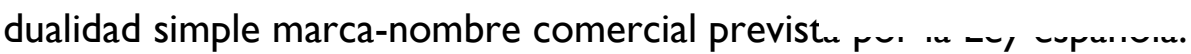

En cualquier caso, el contenido de esta prohibición está en sintonía con lo previsto por el artículo 6 I de la Ley 380, conforme al cual "el titular de un nombre comercial podrá impedir a cualquier tercero usar en el comercio un signo distintivo idéntico al nombre comercial protegido, o un signo distintivo semejante cuando ello fuese susceptible de causar confusión a un riesgo de asociación con la empresa del titular o con sus productos o servicios, o pudiera causarle un daño económico 
o comercial injusto, o implicara un aprovechamiento injusto del prestigio del nombre o de la empresa del titular”. En la Ley española la protección dispensada a estos derechos de terceros queda restringida al nombre comercial, dado que los emblemas se subsumen dentro de la topografía o configuración que pueden adoptar tales nombres y los rótulos de establecimiento fueron erradicados del Derecho español de los signos distintivos defiriendo su protección a la normativa general sobre competencia desleal. En consecuencia, se impide el registro como marca (artículo 7.I de la Ley 17/200I) de los signos que sean idénticos a un nombre comercial anterior que designe actividades idénticas a los productos o servicios para los que se solicita la marca y de aquellos que por ser idénticos o semejantes a un nombre comercial anterior y por ser idénticas o similares las actividades que designa a los productos o servicios para los que se solicita la marca, exista un riesgo de confusión en el público (riesgo de confusión en el que se incluye el riesgo de asociación con el nombre comercial anterior).

d) Inclusión en el signo de una denominación de origen protegida para los mismos productos o para productos diferentes, cuando pudiera causar un riesgo de confusión o de asociación con dicha denominación o implique un aprovechamiento injusto de su notoriedad: Las denominaciones de origen, aun incluidas dentro de las modalidades de propiedad industrial, han gozado tradicionalmente en el Derecho español de cierta sustantividad y autonomía, y su régimen jurídico viene a caracterizarse por el sometimiento a una serie de procedimientos de control cuyo objetivo último es el de garantizar la fidelidad y el acomodo del producto a las características y niveles de calidad que determinaron su calificación como denominación. Tal y como ha destacado la mejor doctrina industrialista española (Fernández-Nóvoa, C (2004) p. 191) "el empleo de indicaciones y nombres geográficos es frecuente en el tráfico económico justamente porque se trata de un mecanismo cuyo aprendizaje resulta relativamente sencillo".

La protección natural de las denominaciones de origen en la normativa marcaria española encuentra su acomodo en la letra $h$ ) del artículo 5.l de la Ley de Marcas que, en sede de prohibiciones absolutas, prohíbe el registro como marca de los signos que "aplicados a identificar vinos o bebidas espirituosas contengan o consistan en indicaciones de procedencia geográfica que identifiquen vinos o bebidas espirituosas que no tengan esa procedencia, incluso cuando se indique el verdadero origen del producto o se utilice la indicación geográfica traducida o acompañada de expresiones tales como clase, tipo estilo, imitación u otras análogas”. El Derecho nicaragüense regula con mayor amplitud y extensión las denominaciones de origen y, además de establecer su concepto en el artículo 2, dedica a su régimen jurídico los artículos $7 \mathrm{I}$ a 78 . La prohibición relativa en cuestión ampara, por consiguiente, el $c \quad$ es o fabricantes, que serán los titulares habituales de las denominacic , para oponerse al registro de marcas posteriores que pudieran geneı............ que resultan titulares.

e) Supuestos residuales de protección: De la regulación realizada por el Derecho nicaragüense cabe destacar, finalmente, dos supuestos de prohibiciones relativas que podríamos calificar como residuales o, en cierta medida, elementos de cierre del sistema. En primer lugar, el apartado h) del artículo 8 de la Ley 380, al que nos hemos referido anteriormente al exponer la prohibición del registro de marcas que lesionen los derechos de autor de terceros, impide igualmente el registro 
como marca de los signos que sean contrarios a "un derecho de propiedad industrial, propiedad de un tercero, protegido por una figura distinta a las reguladas en la presente Ley”. En realidad se trata de una norma destinada a gozar de una aplicación práctica francamente escasa, por cuanto la Ley 380 contiene, como hemos expuesto, una regulación realmente amplia y diversificada de los signos distintivos que abarca, junto con las marcas y nombre comerciales tradicionales, los emblemas, rótulos y denominaciones.

Por lo tanto, esos otros derechos de propiedad industrial a los que se refiere la Ley quedan prácticamente reducidos de hecho al otro gran subsector integrante de la propiedad industrial constituido por las creaciones industriales $y$, en concreto, por los diseños industriales, que es la modalidad respecto de la que mejor cabe imaginar la hipótesis de colisión con una marca posterior, colisión más complicada teóricamente en el supuesto de patentes o modelos de utilidad. En segundo lugar, la letra i) del artículo 8 de la Ley 380 añade un último supuesto de prohibición relativa que resulta un tanto anómalo dentro del ordenado y sistemático elenco de prohibiciones establecidas por este precepto. Conforme a ella se entiende afectado el derecho anterior de un tercero en el caso de "que el signo solicitado sea idéntico o similar a un signo que ha venido siendo usado de buena fe en el territorio nacional por un tercero, en la identificación de los mismos productos o servicios". Se refiere por tanto el supuesto a la hipótesis de las marcas anteriores usadas y no registradas, siempre que dicho uso se haya acomodado a las exigencias de la buena fe y sin ánimo lesivo ni de provocación de daño o perjuicio de terceros.

No obstante, en tanto en cuanto únicamente se exige el mero uso anterior sin precisar por añadidura particulares exigencias de intensidad o duración en dicho uso la doctrina industrialista ha manifestado que esta protección resulta excesiva y puede generar conflictos. Así es para Hernández, M. (La registrabilidad de la marca en Derecho nicaragüense. 22 de septiembre de 2016, recuperado de Universidad de Alcalá de Henares Sitio web: http://hdl.handle.net//0017/20568), p. 407) que considera desacertado el ámbito de protección conferido por esta norma y reitera su "postura en contra de la protección otorgada por esta prohibición a las marcas ordinarias simplemente usadas, pues, desde nuestro punto de vista esta protección resulta excesiva. Como ya advertimos anteriormente, esta protección podría generar conflictos, por ejemplo, entre una persona que haya realizado un breve uso anterior de la marca en una región concreta del mercado nicaragüense y un solicitante posterior. No hay que perder de vista que estamos hablando de un uso que no necesariamente ha de ser intenso y para el que no se exige la adquisición de notoriedad, frente a los intereses del solicitante de la marca, que no tiene por qué conocer la existencia de la marca usada anteriormente dada su escasa relevancia en el mercado".

ISSN 1993-4505 / No. 21, 2016 / Barrero Rodríguez

\section{Consideración final}

Este análisis comparativo que hemos realizado hasta el momento bien puede concluir, como cierre de este estudio, con una breve consideración final a manera de conclusión. Los sistemas marcarios español y nicaragüense se insertan en tradiciones jurídicas diversas y evidencian, naturalmente, influencias y condicionantes de muy diverso signo. En España, la evolución de la normativa de marcas, desde la 
derogación de la Ley inicial 32/1988, ha venido fuertemente impulsada y condicionada por las exigencias de integración europea y por el contenido de las directivas comunitarias, debiendo destacarse como últimas de las aprobadas la Directiva (UE) 2015/2436 del Parlamento Europeo y del Consejo, de 16 de diciembre de 2015, relativa a la aproximación de las legislaciones de los Estados miembros en materia de marcas. Por el contrario, en Nicaragua ha presentado una importancia decisiva el Convenio Centroamericano para la Protección de la Propiedad Industrial (Marcas, Nombres Comerciales, Señales o Expresiones de Propaganda) suscrito el I de junio de 1968 y publicado en La Gaceta número 270 de 1968 y, muy en particular, el Protocolo de Modificación a dicho Convenio suscrito el 30 de noviembre de 1994 y ratificado por Nicaragua por Decreto I7/1996 publicado en La Gaceta de 30 de diciembre del mismo año. También cabe destacar la influencia en la legislación marcaria nicaragüense del Tratado de Libre Comercio entre Centroamérica, Estado Unidos y República Dominicana, firmado el 5 de agosto de 2004 y vigente en Nicaragua desde I de abril de 1996.

Esta diversidad de influencias y de itinerario en la gestación y decantación de las respectivas normativas determina algunas diferencias generales. En España la regulación de los signos distintivos ha tendido a comprimirse, mediante la supresión de la categoría tradicional de los rótulos y la reducción de los signos distintivos a la clásica dualidad entre marcas y nombres comerciales; por el contrario, Nicaragua ha mantenido la flexible diversificación de su mosaico plural de signos distintivos que sigue abarcando los rótulos e integra igualmente a los emblemas, las denominaciones de origen o las señales o expresiones de publicidad comercial. Más allá de esta diferencia general, traducida en la propia rúbrica de las respectivas Leyes reguladoras, las normativas presentan una evidente concomitancia e identidad de sentido, sin perjuicio de algunas diferencias de calado como, en la formulación del concepto de marca, la ausencia de referencia en el Derecho nicaragüense al requisito de la susceptibilidad de la representación gráfica en consonancia con la muy flexible, avanzada y diríamos que pionera tolerancia del Derecho nicaragüense con el registro de los signos perceptibles, incluyendo a los olores o la falta de recepción expresa en la normativa centroamericana de la diferencia expresa entre marcas notorias y renombradas que puede plantear una serie de dudas interpretativas que podrían haber sido evitadas de acoger expresamente dicha distinción.

Estas consideraciones sobre la diversidad de matices y extremos concretos en algunos ámbitos de las normas reguladoras de los signos distintivos no empaña la consideración y alta valoración de ambos textos legales, leyes hermanas en los cronológico (ambas de 200I) y hermanas en el espíritu (el deseo de dotar de una regulación cabal y coherente a ese sector tan crucial y estimulante de la competencia empresarial como es el Derecho de marcas). como corresnonde a naciones igualmente hermanas que deben avanzar, más allá de distancias mercantil en un contexto cada vez más o de la deseable unidad del Derecho

\section{Lista de referencias}

Areán, M. (1995). Tres apuntes sobre la notoriedad y el prestigio de las marcas. En Estudios de Derecho mercantil en homenaje al profesor Manuel Broseta Pont (I75-190). Valencia: Tirant Lo Blanch.

Arroyo, I. (2002). Consideraciones sobre algunas novedades de la Ley 17//200I, de 7 de diciembre, de Marcas. Revista de Derecho mercantil, 243, 15-43. 
Barrero, E. (2002). Algunos aspectos de la reforma del Derecho español de los signos distintivos. Consideraciones sobre la Ley 17/200I, de Marcas. Revista de Derecho mercantil, 245, pp. I4251460.

(2016). Hacia un nuevo régimen jurídico de la creación industrial. Madrid: Marcial Pons.

Botana, M. (1989-1990). Panorámica de la Ley 32/1988 española de Marcas. Actas de Derecho industrial, 13, 13-40.

Bendaña-Guerrero, G.J. (20I I). Reformas y adiciones a la Ley de Marcas y Otros Signos Distintivo. Incidencia del CAFTA-DR. Revista de Derecho, I5, I25-I43.

Casado, A. (200I). La nueva Ley española de marcas: análisis desde la perspectiva del Derecho comunitario. Actas de Derecho industrial, XXII, 23-49.

De Javier, L. (200I). La protección reforzada de la marca notoria y la marca renombrada. 26 de septiembre de 2016, recuperado de Oficina Española de Patentes y Marcas Sitio web: www.oepm.es/cs/OEPMSite/contenidos/ponen/ponencias jilm.

Fernández-Nóvoa, C. (1990). Derecho de Marcas. Madrid: Montecorvo.

(2004). Tratado sobre Derecho de Marcas. Madrid: Marcial Pons.

Galán, E. (2003). Artículo 34. Derechos conferidos por la marca. En Comentarios a la Ley de Marcas. Navarra: Thomson Aranzadi.

González, L.V. (20I3). Consideraciones legales sobre vacíos jurídicos de la ley 380 "ley de marcas y otros signos distintivos" desde el derecho comparado. 13 de septiembre de 2016, de Universidad Centroamericana, sitio web: http://repositorio.uca.edu.ni/65.

Hernández, M. (2008). Los nuevos productos y las marcas olfativas. Anuario de la Facultad de Derecho (Universidad de Alcalá), I, I39-I63.

La registrabilidad de la marca en Derecho nicaragüense. 19 de septiembre de 2016, de Universidad de Alcalá de Henares Sitio web: http://hdl.handle.net/I0017/20568,

Lema, C. \& Fernández, P. (20I3). La marca y las denominaciones de origen. En Derecho mercantil, volumen $2^{\circ}$ (I7I-194). Madrid: Marcial Pons.

Massaguer, J. (200I). "La protección jurídica de las marcas notorias y renombradas en la Ley de Marcas de 200I”. Actas de Derecho industrial, 22, I43-I80.

Monteagudo, M. (1993). El riesgo de confusión en Derecho de marcas y en Derecho contra la competencia desleal. Actas de Derecho industrial, I5, 73-108.

Olivencia, M. (2007, septiembre 25). Globalización y Derecho. Diario ABC, p. 3.

Otero, J.M. (200I). La definición legal de marca en la nueva Ley española de marcas. Actas de Derecho industrial, XXII, 195-2I3.

(2002). La nueva Ley de Marcas de 7 de diciembre de 200I. Revista Juridíca de Cataluña, III, 663-686.

Peña, J.M. (20l0). El alcance del inciso "b)" del artículo 8 de la Ley de Marcas nicaragüense: De los ángulos del principio de especialidad a los supuestos de confusión-asociación y marcas inadmisibles. Revista de Derecho, 13, 99-140.

Robleto, C. \& Hermida, V. (2008). Derecho de la propiedad intelectual. Managua: Universidad Centroamericana. 